\title{
Countermeasures Analysis on Removing the Excess Production Capacity of Yunnan State-Own Iron and Steel Corporation
}

\author{
Keyi Zhao ${ }^{1, \text { a }}$ \\ ${ }^{1}$ Oxbridge College, Kunming University of Science and Technology 1268 north Haiyuan Road, \\ Kunming, Yunnan, 650106 \\ aemail,
}

\begin{abstract}
In recent years, Chinese iron and steel industry has gone through a tough period of time, due to the huge excess production capacity and the relatively low market demand. Along with the building market demands cooling down, the consumption of crude steel are constantly decreasing. The state council noted that China will cut crude steel production capacity by 100 to 150 million tons in five years. Under this circumstance, the KISC Corporate, as a state owned corporation, is one of the steel overcapacity members in the industry as well. This article based on the reality of the KISC Corporation steel excess production capacity, by looking back the measures of the corporation and the local governments' policies, to analyze the effectiveness of the countermeasures for solving the overcapacity. Hopefully to find a feasible way to remove the excess capacity without serious unemployment.
\end{abstract}

\section{Introduction}

After years of economic development, there are fifty six steel production enterprises in Yunnan, and only one of them are state-owned. In order to resolve the problem of excess production capability arose from 2013, provincial government started to adopt the "cutting overcapacity" policy, which made by the central government of China in 2016. As a reflection of the policy, forty four companies were closed by the government last year, as a result of the pollution and the over production of low quality goods. And now, only the KISC (short for Kunming Iron and Steel Corporation), a state-owned enterprise, is producing in Yunnan.

The nature of iron and steel industry make the industry constantly requires huge amount of capital and technology. And iron and steel producers with less capital and technology, normally they are private enterprises in China, which would less capable to provide high tech and Eco-friendly products. Therefore, the policy adopted now is mainly imposed on the overcapacity private enterprises. As for the state-owned enterprise-KISC, the earliest overcapacity was observed around 2013. Since then it started to cut out the high pollution invalid production capacity. Due to the gradually decline of real estate market demand, three years later, the steel industry capacity became more and more excessive within China, including all the valid and invalid production. In order to response to government's requirement about cutting the excess production capacity, the corporation shut down seven blast furnaces (the total volume of 6420 cubic meters), five converters (three of them, 32 tons each; two of them, 50 tons each ), six steel converters, as well as all related equipment and facilities for sintering and rolling. The seven closed down blast furnaces are still in line with national industry standards, which mean the products they made are valid but excess. The shutting down behavior reduces 2.8 million tons crude steel, accounts for more than $74 \%$ of the total production cutting down task in Yunnan. For the equipment that was taken down, the company's board of directors is seeking international production capacity cooperation aboard, such 
as Vietnam, Myanmar and Nigeria, expecting to find new owners for the equipment. After the adjustment, there are four blast furnaces still in function, one in the Anning headquarter, one in the Caopu new production area, one in the Honghe Iron and Steel corporation and the last one in the Yuxi Xinxing Iron and Steel corporation. The reason for keeping the four blast furnaces fully function is that their operating indicators in accordance with domestic advance standard, which makes the more efficient production. Products cost is lower than before, at least saving 150-180 Yuan per ton. In the future, the company management has decided to focus on providing the high-end steel products for the market that lack of valid supply, such as military, automobile industry and so forth. At the same time, conduct the powder metallurgy new material research, the cross border logistic and the international E-commerce to expand current market.

\section{The Production Capacity Changes Overview}

Kunming Iron and Steel Corporation (short for "KISC”) established in 1939. It has been in operation more than 80 years. For the sake of optimizing resource allocation and taking full advantage of sufficient capital and technology of eastern China, approved by Yunnan provincial government, the corporation did the strategic reorganization with Wuhan Iron and Steel Corporation in 2007. Since then the production efficiency and technological standard has been improved. For instance, the large scale metallurgical equipment has been used; the information technology has been used in sales and producing process. After implementing the "cutting capacity policy", there are three main iron and steel production base in the corporation, Anning, Honghe and Yuxi, with 10 million tons annual output as a whole. It is the main supplier of mineral and steel in Yunnan. The products have a high reputation in Yunnan and southwest China, especially in the building steel market. With the aim of diversification, besides the six iron and steel production subsidiaries, there are some joined ventures built up for fostering non-steel business, such as modern logistic, energy conservation and environment protection, equipment manufactory, mining, cement manufactory, cultural tourism, real estate, pension industry, E-commerce, financial service, etc.

With the influence of soaring demand in real estate market and infrastructure construction in west China from 2009-2013, the iron and construction steel were very popular at that time in domestic market. In 2009, the total consumption of steel is 10.04 million tons in Yunnan, and in 2013 it reaches the peak of 19.51 million tons. However, the market share of KISC brand was falling in construction steel market, due to the fierce competition, as shown in figure 1. From 2009 to 2015, the market share of construction steel, also known as crude steel, is respectively $65.0 \%$, $61.4 \%$, 51.9\%, 48.5\%, 49.1\%, 51.8\% and 53.9\%. 


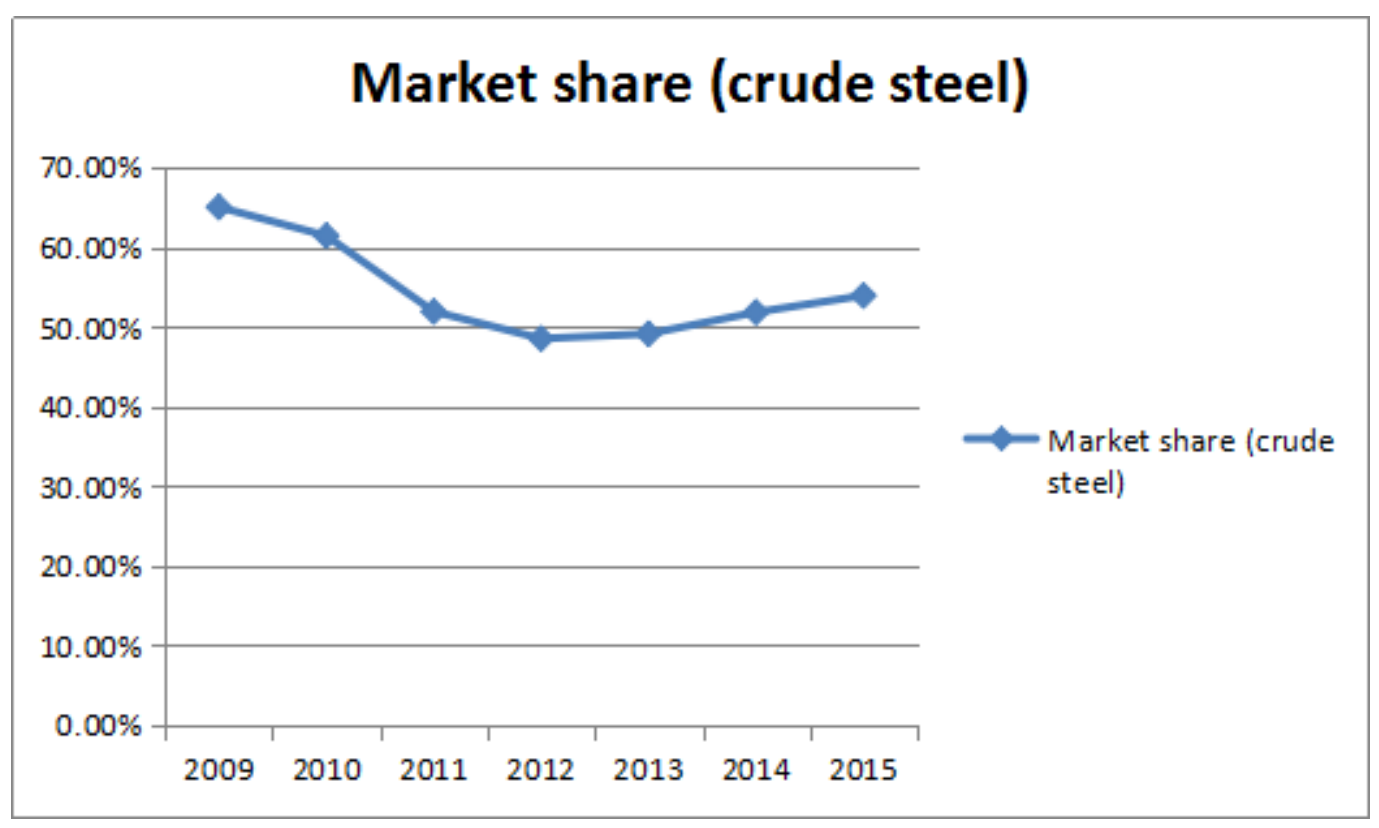

Figure 1: Market share of crude steel in Yunnan province

The reason for the corporation's market share decline is that, since 2009, the private iron and steel enterprises seized the market by adopting the low-price competition strategy, which increased massive new capacity. In order to regain the market share, the corporation made a series of efforts, such as innovate the marketing system, upgrade customer services, fine-tune the customer structure, and the price system. And the market share raise up again in 2013 and the following two years, as shown in Figure1. Suffering from the effect of steel market demand decline within the province in 2015, the market share still failed to restore the 2009 level.

In addition, the excess production capacity also can be observed in the annual production capacity utilization change figures, as shown in Table 1. In 2009 and 2010, the output and sales of the iron, crude steel and steel was increasing, and none of them in stock. Despite the declining market share (as shown in Figure 1), there was no obvious production overcapacity. After 2011, affected by the raising market demand, the capacity and output of the three kinds of steel products has increased correspondingly, so did the inventory. Firstly, the rate of capacity utilization reached up to $90.40 \%$ in 2010 , then gradually fell in the following years. Along with the real estate market consumption drop up, the market demand of crude steel was recessing. In 2015, the crude steel inventory was about 0.211 million tons, the capacity utilization rate decrease to $64.92 \%$, which means the excess production started to expose in Yunnan. 
Table1: Annual capacity utilization change from 2009 to 2015

\begin{tabular}{|c|c|c|c|c|c|c|c|c|c|c|}
\hline \multirow[t]{2}{*}{ Year } & \multicolumn{2}{|c|}{ Iron(MT/year) } & \multicolumn{3}{|c|}{ Crude steel(MT/year) } & \multicolumn{4}{|c|}{ Steel(MT/year) } & \multirow{2}{*}{$\begin{array}{l}\text { capacity } \\
\text { utilizatio } \\
\text { n rate }\end{array}$} \\
\hline & $\begin{array}{l}\text { capacit } \\
\text { y }\end{array}$ & output & capacity & output & stock & $\begin{array}{l}\text { capacit } \\
\text { y }\end{array}$ & output & sale & stock & \\
\hline $\begin{array}{l}200 \\
9\end{array}$ & 572.20 & $\begin{array}{l}569.9 \\
9\end{array}$ & 686.5 & $\begin{array}{l}573.3 \\
5\end{array}$ & & 642.00 & $\begin{array}{l}525.3 \\
9\end{array}$ & $\begin{array}{l}644.2 \\
9\end{array}$ & & 83.52 \\
\hline $\begin{array}{l}201 \\
0\end{array}$ & 551.20 & $\begin{array}{l}615.1 \\
2\end{array}$ & 686.5 & $\begin{array}{l}620.6 \\
2\end{array}$ & & 622.00 & $\begin{array}{l}609.8 \\
4\end{array}$ & $\begin{array}{l}707.2 \\
3\end{array}$ & & 90.40 \\
\hline 2011 & 633.80 & $\begin{array}{l}587.0 \\
3 \\
\end{array}$ & 685.00 & $\begin{array}{l}603.6 \\
8 \\
\end{array}$ & 8.48 & 691.20 & $\begin{array}{l}703.8 \\
5 \\
\end{array}$ & $\begin{array}{l}663.2 \\
9 \\
\end{array}$ & $\begin{array}{l}21.3 \\
6 \\
\end{array}$ & 88.13 \\
\hline $\begin{array}{l}201 \\
2\end{array}$ & 833.80 & $\begin{array}{l}661.2 \\
7\end{array}$ & $\begin{array}{l}1,079.0 \\
0\end{array}$ & $\begin{array}{l}654.8 \\
0\end{array}$ & $\begin{array}{l}32.6 \\
2\end{array}$ & 851.20 & $\begin{array}{l}677.8 \\
6\end{array}$ & $\begin{array}{l}660.4 \\
2\end{array}$ & $\begin{array}{l}28.0 \\
1\end{array}$ & 60.69 \\
\hline $\begin{array}{l}201 \\
3 \\
\end{array}$ & 833.80 & $\begin{array}{l}840.2 \\
5 \\
\end{array}$ & $\begin{array}{l}1,079.0 \\
0\end{array}$ & $\begin{array}{l}828.8 \\
8 \\
\end{array}$ & $\begin{array}{l}22.5 \\
8 \\
\end{array}$ & 851.20 & $\begin{array}{l}844.9 \\
2 \\
\end{array}$ & $\begin{array}{l}849.5 \\
4 \\
\end{array}$ & $\begin{array}{l}22.6 \\
3 \\
\end{array}$ & 76.82 \\
\hline $\begin{array}{l}201 \\
4\end{array}$ & 833.80 & $\begin{array}{l}769.6 \\
3\end{array}$ & $\begin{array}{l}1,079.0 \\
0\end{array}$ & $\begin{array}{l}765.8 \\
9\end{array}$ & $\begin{array}{l}16.4 \\
8\end{array}$ & 846.20 & $\begin{array}{l}802.8 \\
8\end{array}$ & $\begin{array}{l}804.4 \\
8\end{array}$ & $\begin{array}{l}29.4 \\
9\end{array}$ & 70.98 \\
\hline $\begin{array}{l}201 \\
5\end{array}$ & 833.80 & $\begin{array}{l}698.3 \\
3\end{array}$ & $\begin{array}{l}1,079.0 \\
0\end{array}$ & $\begin{array}{l}700.5 \\
3\end{array}$ & $\begin{array}{l}21.1 \\
0\end{array}$ & 836.20 & $\begin{array}{l}682.8 \\
6\end{array}$ & $\begin{array}{l}682.7 \\
8\end{array}$ & $\begin{array}{l}26.4 \\
7\end{array}$ & 64.92 \\
\hline
\end{tabular}

Source: People’s bank of China Anning City branch, group working report, 20171.

At the end of 2015, the total assets of KISC was approximately 56.57 billion Yuan, liability 39.92 billion Yuan, the asset liability ratio is around 70.5\%, 14463 employees; sales income was 37.81billion Yuan, total loss was 3.71 billion Yuan. So in 2016, the corporation began to cut down the excess production capacity as a response to the national policy. The three types of steel output has been reduced respectively by 0.6632 million tons, 0.6011 million tons and 0.3793 million tons, which is 6.3201 million tons, 6.3 million tons, 6.4493 million tons. Until the first quarter of this year, the sales income rose up by 6.25 billion Yuan, and net earnings was12.62 million Yuan. Eventually, the corporation starts to make a profit instead of suffering a loss. 2

\section{Corporate Measures to Solve the Excess Production Capacity}

With respect of the business management, the corporation should carry out the following measures to solve the overcapacity. Firstly, shut down the production facilities of low efficiency and high pollution. As the matter of fact, the KISC did reduce the excess capacity of 2.8 million tons steel. And the production capacity of the steel supporting industries was cut down as well. For instance, the capacity of iron was reduce by 0.535 million tons, the iron alloy was reduced by 0.2 million tons, the iron ore concentrate was reduced by 1.3 million tons and the coke was reduced by 1.8 million tons.

Secondly, integrate the inner resources for production and promote the development of non-steel industries. In the process of upgrading and transformation, the corporation has already opened some 200 subsidiaries and branches, of all sizes for business. But too many small scale subsidiaries and

\footnotetext{
1 YANG Yunguang, LIAO Yuan, YU Shuifeng and LI Xingyan ,"The Status Quo, Causes and Countermeasures of Overcapacity of Iron and Steel Industry in Anning City”, Times Finance,China, 2017(01):285-288

2 All the figures are sorted out from the audit reports of KISC in 2015 and 2016.
} 
branches existed, some of them were playing the same role, which is a waste of resources. Therefore, the corporation decided to accelerate the assets integration, that have recombined the assets of 187 subsidiaries and branches since 2016. Meanwhile it focuses on modern logistic, new energy, cultural tourism, environment protection, construction, finance and people's livelihood, serving for the local economy development. For example, established the Yunnan Kunming Assets management company to manage the land and building, Kunming coking gas plant living area, Luoci fleet, automobile transport branch, and so forth, total involve 8.6 billion Yuan. As for the financial and trade services, operate by Yunnan KISC Financial holding group Co.Ltd. For cultivating the energy-saving and environment protection industry and integrating the branches of the KISC environment, energy technology, water purification, industry hygiene, and so forth, the Yunnan Tianlang energy saving and environment protection group Co.Ltd is set up.In order to enhance the competitiveness of new material products and build in a new, cluster, high-end material production industry, the Yunnan KISC new material group Co.Ltd is established. Reorganize the Yunnan Huayun Industry Group Co.Ltd. for developing service industry, such as agricultural sightseeing and leisure, property management, security services and so on. For people' s livelihood and social services, like tourism and hotel services, culture and advertising services, aviation services and so forth, establish the Yunnan KISC culture and tourism group Co.Ltd. As for speeding up the electronic information industry development, the KISC electronic information Co.Ltd is established.

Thirdly, enhance the cooperation with the outsiders; improving the production structure and providing useful products. In terms of structure optimizing, the corporate is supposed to stop chasing the scale of production capacity, but stick to the strategy of diversification and refining. Increasing the new products research such as anti-seismic steel, residential steel, fire-resistant, weather resistant, high strengths low density steel produsts provided for automobile, ships and military. At the same time, extending the industry chain, by building the multilevel parking garage, elevators, factory disguised style houses and so on.

Forth, make further efforts to developing iron and steel logistic for lowering the transportation costs. Kunmming Wang Jia Ying logistic park is located in the Kunming economic development zone, covers an area of 1000 acres. It is the largest logistic demonstration park in Southwest China.

Fifth, explore the foreign market by using the "one belt one road strategy”, seize the opportunity to establish the trade hub towards Southeast Asia at Yunnan. Based on the Vietnam old street steel industry cooperation program, proceed with the international production capacity cooperation. Push forward the equipment and technology internationalization.

Besides, in solving the problem of employments of overcapacity industry, the human resource of the corporation adjusts the number of workers, keeping the number under 10000. More specifically, deduct $50 \%$ of regular employees, dismiss all the contract employees. Reduce management hierarchy, streamline administration, merge management positions, and improve management efficiency. Staff members will take up a job through competition. Conduct labor contract management, in conformity with legal provisions; terminate the labor contract with the unqualified employees through assessment in all respects. Furthermore, establish human resource and employment services center, and use the flexible schedule to allocate staffs in position.

In 2016, total 4358 staffs were reallocated. The details are as follow: 1722 unemployed staffs find a new job through the employment service center and business incubator; 2242 employees 
inner retired, 53 employees resigned, 16 employees retain their jobs but suspended the salary, 7 employees apply for vacation, 3 employees give up the job position because the disability, 315 employees were dismissed. There are still 13,000 staffs in the overcapacity industry waiting to be reallocated in 2017.

\section{Local Government Measures to Solve the Excess Production Capacity}

According to the national policy, local government at all levels provide matching fund according to 1:1 proportion. The matching fund is both from provincial government and local government, each of them bear 50\%. Eliminate the least environmental friendly, high energy consumption, unsafe steel producers by governmental administration means. Through the accountability system, social supervision, strict law enforcement, pushes forward the case investigation and implementation. Bring the implementation outcome into local government assessment system, then announce to the public. Prohibit the new production capacity arise and make sure removing the overcapacity. Serving for the purpose of reduce production capacity, there a series of matching policies are made by provincial government, involving tax, finance, staff resettlement, land, environment protection, product quality, safety and so forth. Under the guidance of provincial government policies, the Anning city government's measures are as follow: coordinate the relations between local commercial banks and the KISC. Represent the KISC, The Anning branch of China construction bank and Shanghai Pudong Development Bank to issue corporate bonds respectively 2.5 billion Yuan and 1.5 billion Yuan. Issue the single claims trust bonds, and use Build-Transfer, Build-Operation-Transfer sort of operation mode to drive on the infrastructure construction, to provide financial assistance for the corporate upgrading and transformation. Other than that, under the directing of the local government, financial institutions are assisting the steel producers pulling through the difficulties by extending credit, loan restructuring, providing funds to support corporate transformation etc. The financial institutions in Anning are working with the local government and regulatory department to help the iron and steel corporations who are in trouble because of the production overcapacity. Lay down the specific policies, according to corporations' different situation, to alleviate the pressure of the corporation, by adopting preferential interest rate, adjusting the period and types of loan, paying interest on the annual basis etc.

\section{Conclusion}

The KISC Corporation starts to make profit after the implementation of the cutting excess capacity policy in 2016. So it is a desirable option for the corporation to conduct inner reform, combine the production resources, and increase the fund and resources utilization rate. In solving the staff resettlement and unemployment problem, the corporation adopts the diversification and encourages non-steel industries development, to absorb unemployed workers. It is desirable as well. For instance, since last year, the pension service industry has developed as a representative of diversification. The establishment of the KISC pension service center meets most retirees' requirements as well as provides more job opportunities to the newly unemployed workers. However, the very existence of the corporation basically depends on the industrial structure reforming and upgrading. It requires tons of technology and time to upgrade and innovate. For any domestic corporation, it is impossible to achieve in a short period of time. In the short time, the corporation mainly through expending sales market, both domestic and foreign market, to digest 
excess production capacity and inventories. But due to the local protectionism, it is difficult to compose a unified market, which means corporations cannot ease the overcapacity through the flow of goods among provinces. Besides, in recent year the demands of international steel market are constant shrinking, which results in the corporation could not reduce the overcapacity by exporting. The KISC Corporation has already made the exploration towards Southeast Asia market by engaging in the local infrastructure construction and mineral exploit, but the international trade structure and comparative advantages laws indicates that, in removing the excess production capacity, trade with the least developing countries in Southeast Asia can only help a little. So the "one belt one road" national economic development proposition and related policies are the opportunities for the corporation to expand market. Explore the market of south Asia and push forward the export of heavy equipment and technology, and then boost the corporation transformation.

With respect of the local government policies, the implementation of removing overcapacity policy would affect the local public financial income and banks' profit to some extent. Started from 2016, the Anning city government had to arrange more than 10 million Yuan to overcome the possible risk, and 10 million subsidize interest, to help corporation to ease the pressure on financing. In the meantime, set up special funds to assist relocating the old factory facilities and completing the development plan of the KISC Corporation. Because of the decreasing tax and increasing financial expenditure, local government may lack of passion to help solving the overcapacity problem, and hold a wait-and-see attitude. In addition, the credit risk of all the banks in Anning, mainly comes from steel corporation, steel and iron ore trade. The steel and iron industry is well known as its poor profitability and low solvency. If the local governments do not pay close attention to the steel corporation, urge the corporation turns loss into profit as soon as possible. It is much likely to trigger the systematic risk within the local bank industry. Therefore, the KISC Corporation should continue conducing transformation and upgrading by adopting the policies and measures in above-mentioned. And pay all the debts on time, reducing the credit risk of local banks. The cutting overcapacity so far is one of the rational choices for the Chinese economy development.

\section{References:}

1. The study of China's Steel Industry overcapacity problem on the background of the supply side reform, A Chen, Journal of industrial technological\& Economics, 2016-10

2. Resolving the overcapacity in iron and steel industry of China under the strategy of "one belt, one road": Basis for trade, investment opportunity and implementation mechanism, ZHAO Ming-liang; YANG Hui-xin, journal of East China Universities and Social Science, 2015-04

3. The state quo and countermeasures of cutting down the production overcapacity of steel industry in Anning, YANG Yun-guang, Times Finance, 2017-03

4. The reality and countermeasures of steel industry overcapacity based on the investigation of 30 steel enterprises, WANG Chun Qiao, Times Finance, 2016-29

5. Bond financing research on overcapacity industry based on the bond financing instruments issuance, FAN Kai, FAN Ye, Modern management science, 2017-02 